\title{
Comparison between hysterosalpingography and laparoscopic chromopertubation for the assessment of tubal patency in infertile women
}

\author{
Anjana Choudhary, Shreya Tiwari*
}

Department of Obstetrics and Gynecology, CCM Medical College, Kachandur, Durg, Chhattisgarh, India

Received: 07 September 2017

Accepted: 22 September 2017

\section{*Correspondence:}

Dr. Shreya Tiwari,

E-mail: shreyatiwari2910@gmail.com

Copyright: (C) the author(s), publisher and licensee Medip Academy. This is an open-access article distributed under the terms of the Creative Commons Attribution Non-Commercial License, which permits unrestricted non-commercial use, distribution, and reproduction in any medium, provided the original work is properly cited.

\section{ABSTRACT}

Background: Infertility is a critical component of reproductive health, and has often been neglected in these efforts. The inability to have children affects men and women across the globe. Infertility can lead to distress and depression, as well as discrimination and ostracism. Hysterosalpingography (HSG) of infertile women is useful for the assessment of structure of uterine cavity, tubes and their patency. However, although a more invasive procedure such as laparoscopy $(\mathrm{L} / \mathrm{S})$ which is regarded as the most reliable method in detection of tubal pathologies in infertility.

Methods: This was a Prospective cross sectional study of 50 patients with history of primary or secondary infertility selected from IPD of Jawaharlal Nehru medical College and Acharya Vinobha Bhave Rural Hospital, Tertiary Health Care Centre Located in Sawangi, Wardha, Maharashtra (India). The age group of the patients was between 18 yrs. $45 \mathrm{yrs}$. The study population was selected depending upon the total number of patients (fitting the criteria) visiting the IPD of AVBRH Department of Obstetrics and gynecology for a period of 1 years (September 2015 to September 2016). The collected data was compiled and proper statistical formulas were applied to analyze the data collected.

Results: The present study include 50 cases of both primary and secondary infertility of which 29 cases (58\%) were primary infertility and 21 cases $(42 \%)$ were secondary infertility. In this study the $3(6 \%)$ cases were found in the age group of $<20$ years followed by 16 (32\%) cases in the age group of 21-25 years, 19(38\%) cases were in the age group of 26-30 years while $7(14 \%)$ cases were in the age group of 31-35years the age group of 36-40 years $2(14 \%)$ and in age group $>40$ years is $3(6 \%)$. In the present study, based on Kuppuswamy index most (30\%) of the women had class IV socio economic status in both primary and secondary infertility. In the present study, there were $6(28.57 \%)$ cases with History of LSCS, 7 cases $(33.33 \%)$ had FTND, 6(28.57\%) cases had history of abortion, and 2(9.52\%) had previous ectopic pregnancy. Moderate degree of agreement was found between findings of both tests.

Conclusions: The results suggest that hysterosalpingography is useful as a primary screening procedure, but laparoscopy provides a more accurate assessment of tubal patency in the investigation of infertility.

Keywords: Hysterosalpingography, Laparoscopy, Tubal patency

\section{INTRODUCTION}

Infertility is a critical component of reproductive health, and has often been neglected in these efforts. ${ }^{1}$ The inability to have children affects men and women across the globe. Infertility can lead to distress and depression, as well as discrimination and ostracism. ${ }^{1,2}$

Approximately $15 \%$ of couples are affected by infertility, Common causes of infertility include male 
factor (45\%), ovulation disorders (37\%) and tubal damage (18\%). A combination of several factors is found in approximately $20 \%$ of all couples worldwide. ${ }^{3}$

Tubo-peritoneal factors are responsible for about 30-40\% of cases of female infertility and hence evaluation of tubal patency represents a key step and a basic investigation in the assessment of infertile women.,5 Tubal occlusion is the most common underlying cause of infertility. ${ }^{6,7}$ In Africa Tubal factor infertility ranges from 42 to $77 \%$ in the literature. ${ }^{8}$

Hysterosalpingography (HSG), laparoscopy with chromopertubation or both can be used to evaluate tubal patency. Owing to its noninvasive nature and low cost, HSG is widely used as a first-line approach to assess tubal patency and uterine anomalies in routine fertility workup. ${ }^{9,10} \quad$ However, laparoscopy with chromopertubation has been the gold standard for investigating tubal patency. ${ }^{10}$

Hysterosalpingography (HSG) of infertile women is useful for the assessment of structure of uterine cavity, tubes and their patency. ${ }^{10}$ However, although a more invasive procedure such as laparoscopy $(\mathrm{L} / \mathrm{S})$ which is regarded as the most reliable method in detection of tubal pathologies in infertility. ${ }^{10}$

Laparoscopic surgery is performed during the follicular phase. During the laparoscopic observation after the assessment of bilateral ovaries, fallopian tube, uterus and other pelvic structures, tubal patency is evaluated by chromopertubation to detect pelvic adhesions, any existence of endometriosis or presence of other pathologies. $^{9}$

The present study is carried out to enhance our knowledge in regards to role of hysterosalphingography and laparoscopic chromopertubation as a safe, effective, cost effective and accurate tool for the assessment and planning the protocol for management of infertility. Since this study was carried out in a rural set up in India to compare the pathophysiological nature of infertility amongst the rural population as well as for women in the Indian subcontinent.

\section{METHODS}

This was a Prospective cross sectional study of 50 patients with history of primary or secondary infertility selected from IPD of Jawaharlal Nehru medical College and Acharya Vinobha Bhave Rural Hospital, Tertiary Health Care Centre Located in Sawangi, Wardha, Maharashtra (India).

The age group of the patients was between 18 yrs. - 45 yrs. The study population was selected depending upon the total number of patients (fitting the criteria) visiting the IPD of AVBRH Department of Obstetrics and
Gynecology for a period of 1 years (September 2015 to September 2016).

\section{Inclusion criteria}

- Those patients coming for treatment of infertility

- Those patients who are given informed consent.

\section{Exclusion criteria}

- Those patients who have not given informed consent

- Women who did not return for laparoscopy evaluation.

- Technical problems related to HSG and women who became pregnant after hysterosalpingography.

- Women with pelvic infection.

As the patient came to the IPD, a detailed history pertaining to infertility and other relevant history was asked and recorded, including the data if patient had previous treatment documents. In this first visit of patient, the couple was explained in detail about the normal physiology and the fertile period.

The female were subjected to clinical examination as well as systemic examination along with local and gynaecological examination. Then they were subjected to certain basic blood investigations, ultrasonography (USG) pelvis and husband's semen analysis; and patient was asked to follow-up with next menstrual cycle. According to the inclusion and exclusion criteria the patients were subjected to Hysterosalphingography and Diagnostic laparoscopy.

Patients selected for Hysterosalphingography and Diagnostic laparoscopic chromopertubation evaluation were admitted in the post menstrual phase. Hysterostrosalphingography done and after 1 month diagnostic laparoscopic chromopertubation for tubal patency ovarian drilling, adhesiolysis etc. were also done if required. All the data was recorded on a predesigned proforma. The collected data was compiled and proper statistical formulas were applied to analyze the data collected.

\section{Statistical analysis}

Statistical analysis was done by using descriptive and inferential statistics using Chi-Square test, binary classification and the software used was SPSS 17.0 version, graph pad prism 5.0 versions and $\mathrm{p}<0.05$ is considered as level of significance.

\section{RESULTS}

The present study include 50 cases of both primary and secondary infertility of which 29 cases (58\%) were primary infertility and 21 cases $(42 \%)$ were secondary infertility (Table 1). 
Table 1: Distribution of patients according to fertility.

\begin{tabular}{|lll|}
\hline Infertility & No. of patients & $\%$ \\
\hline Primary infertility & 29 & 58.00 \\
\hline Secondary infertility & 21 & 42.00 \\
\hline Total & 50 & 100.00 \\
\hline
\end{tabular}

In this study, the $3(6 \%)$ cases were found in the age group of $<20$ years followed by $16(32 \%)$ cases in the age group of $21-25$ years, $19(38 \%)$ cases were in the age group of 26-30 years while $7(14 \%)$ cases were in the age group of 31-35years the age group of 36-40 years 2 $(14 \%)$ and in age group $>40$ years is $3(6 \%)$. The Mean Age is: $28.40 \pm 6.73$ (Table 2).

Table 2: Age wise distribution of patients.

\begin{tabular}{|lll|}
\hline Age $(\mathrm{yrs})$ & No. of patients $(\mathrm{N}=\mathbf{5 0})$ & $\%$ \\
\hline$\leq 20 \mathrm{yrs}$ & 03 & 6.00 \\
\hline $21-25 \mathrm{yrs}$ & 16 & 32.00 \\
\hline $26-30 \mathrm{yrs}$ & 19 & 38.00 \\
\hline $31-35 \mathrm{yrs}$ & 07 & 14.00 \\
\hline $36-40 \mathrm{yrs}$ & 02 & 4.00 \\
\hline$>40 \mathrm{yrs}$ & 03 & 6.00 \\
\hline Total & 50 & 100.00 \\
\hline Mean age & $28.40 \pm 6.73$ & \\
\hline
\end{tabular}

In the present study, based on Kuppuswamy index most (30\%) of the women had class IV socio economic status in both primary and secondary infertility (Table 3 ).

Table 3: Distribution of patients according to socioeconomic status.

\begin{tabular}{|c|c|c|}
\hline $\begin{array}{l}\text { Socio-economic } \\
\text { status }\end{array}$ & $\begin{array}{l}\text { No. of patients } \\
(\mathrm{N}=50)\end{array}$ & $\%$ \\
\hline Lower & 10 & 20.00 \\
\hline Upper lower & 15 & 30.00 \\
\hline Lower middle & 13 & 26.00 \\
\hline Upper middle & 10 & 20.00 \\
\hline Middle & 02 & 4.00 \\
\hline Total & 50 & 100 \\
\hline
\end{tabular}

In the present study, there were $6(28.57 \%)$ cases with History of LSCS, 7 cases $(33.33 \%)$ had FTND, 6 $(28.57 \%)$ cases had history of abortion, and $2(9.52 \%)$ had previous ectopic pregnancy (Table 4).
Table 4: Distribution of patients according to obstetric history of secondary infertility patients.

\begin{tabular}{|lll|}
\hline Obstetric history & No. of patients & $\%$ \\
\hline Previous LSCS & 06 & 28.57 \\
\hline Previous FTND & 07 & 33.33 \\
\hline Previous Abortion & 06 & 28.57 \\
\hline Previous Ectopic & 02 & 9.52 \\
\hline Total & 21 & 100 \\
\hline
\end{tabular}

Table 5: Distribution of patients according to tubal patency in hysterosalphingography and laparoscopic chromopertubation.

\begin{tabular}{|lll|}
\hline Tubal Patency & HSG & $\begin{array}{l}\text { Laparoscopic } \\
\text { chromopertubation }\end{array}$ \\
\hline Bilateral Patency & $28(56 \%)$ & $28(56 \%)$ \\
\hline Unilateral Patency & $08(16 \%)$ & $07(14 \%)$ \\
\hline Bilateral Occlusion & $14(28 \%)$ & $5(10 \%)$ \\
\hline
\end{tabular}

Tubal patency test was done by injection of methylene blue dye through the cervix and visualization of spillage of dye in the peritoneal cavity. Chromopertubation in primary and secondary infertility group was done and in primary infertility group it was observed that 28 cases $(56 \%)$ had B/L patent tubes in Hysterosalphingography, 28 cases $(56 \%)$ had $\mathrm{B} / \mathrm{L}$ patent tubes in diagnostic laproscopic chromopertubation. 8 cases (16\%) had unilateral patency in Hysterosalphingography, 7 cases $(14 \%)$ had unilateral patency in Diagnostic laparoscopic chromopertubation, 14 cases $(28 \%)$ had $\mathrm{B} / \mathrm{L}$ occlusion in Hysterosalphingography and 5 cases (10\%) had B/L occlusion in Diagnostic laproscopic chromopertubation (Table 5).

Table 6: Other findings on Hysterosalphigography.

\begin{tabular}{lll}
$\begin{array}{l}\text { Other Findings } \\
\text { Shape of the uterus }\end{array}$ & No. of patients & $\%$ \\
\hline Didelphys uterus & 1 & 2 \\
\hline Bicornuate uterus & 1 & 2 \\
\hline Septate uterus & 2 & 4 \\
\hline Cavity of uterus & & \\
\hline Endometrial polyp & 2 & 4.00
\end{tabular}

The Hysterosalphingography findings in the present study showed 1 case $(2 \%)$ didelphys uterus, 1 case $(2 \%)$ of bicornuate uterus, 2 cases (4\%) of septate uterus, $2(4 \%)$ cases of endometrial polyp (Table 6).

Table 7: Detection of tubal status at HSG and Laparoscopic chrompertubation.

\begin{tabular}{|lllll|}
\hline HSG & Diagnostic Laparoscopy & $\begin{array}{l}\text { McNemer chi-square test } \\
\text { value }\end{array}$ & p-value \\
\hline Positive & Positive & Negative & & 0.0001, \\
\hline Negative & 29 & 1 & 15.23 & Significant \\
\hline Total & 10 & 10 & & \\
\hline
\end{tabular}


- McNemer chi-square test value - 15.23, $\mathrm{p}<0.0001$ [Significant]

- $\quad$ Positive Likelihood Ratio $=8.18[1.25,53]$

- Negative Likelihood Ratio = 0.28 [0.16, 0.50]

- Cohen's Kappa Index Value $=0.505$

There was a significant association was found between results of two tests. Hysterosalpingography showed a positive-likelihood ratio value for assessment of tubal status of $8.18 \%$, a negative- likelihood ratio value of $0.28 \%$, Moderate degree of agreement was found between findings of both tests (Table 7).

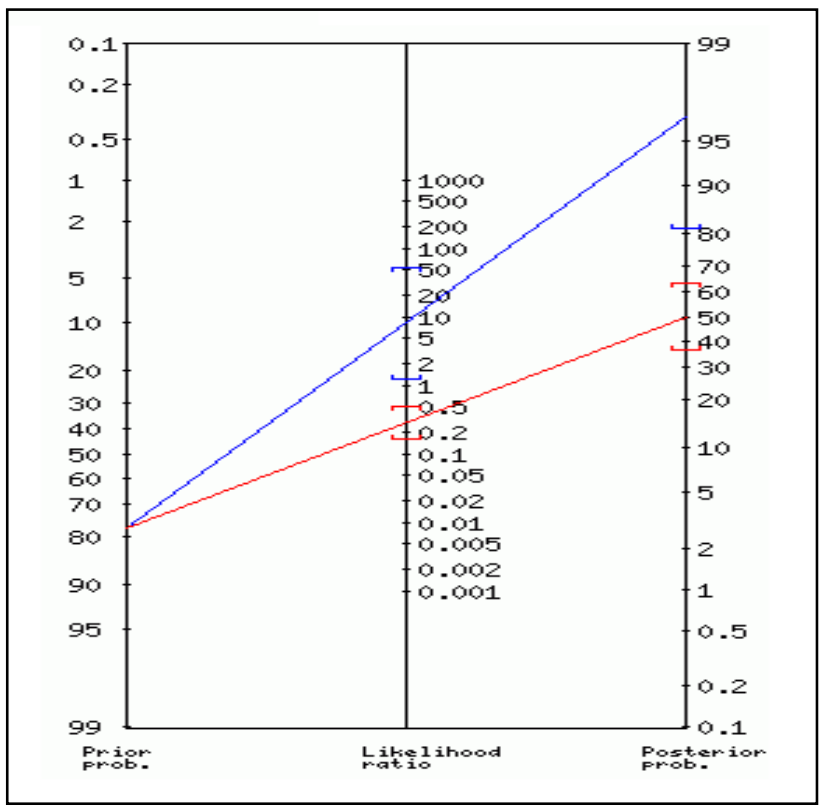

Figure 1: Fagan's nomogram.

\section{DISCUSSION}

Intra cavitary pathology like endometrial polyps, uterine septum, bicornuate uterus often results in abnormal uterine bleeding, infertility or both. Congenital anomalies of the female reproductive system are associated with higher rate of infertility. Hysterosalpingography is a safe relatively inexpensive, simple and rapid diagnostic test, when performed properly provides valuable information about tubes, uterus and the cervix. ${ }^{11}$

World Health Organization studies indicate that laparoscopy identifies tubal patency better than HSG. Nevertheless, both modalities are less than ideal in the accurate identification of tubal status. ${ }^{12}$

In the present study, the commonest age group was 26 to 30 years $(38 \%)$. Primary infertility was mainly seen in the age group of 21-25 years and secondary infertility in 2630 years. The mean age of the study population was $28.40 \pm 6.73$ years. Park $\mathrm{J}$ et al, in their study reported with Participant mean age of 32 years (SD: 2.7), with a range between 26 and 41 years. ${ }^{13}$
Our study shows that (28\%) Bilateral tubal block was detected in Hysterosalphingography and (10\%) in diagnostic laparoscopic chromopertubation. The study by Chakraborti et al $(22.7 \%)$ and Goynumer G et al $(24$ $\%) .{ }^{14,15} 156$ which shows bilateral tubal block to be the common tubal cause of Infertility.

Previous several studies observed that use of HSG in infertile patients provides additional information regarding tubal patency and can be used as a preselection procedure prior to laparoscopic chromopertubation. ${ }^{15-17}$ The finding of the present study was found to be similar with above observations.

The present study indicates that Tubal patency plays a major role for conception in the etiology of infertility and evaluation by laparoscopy along with chromopertubation will give a better idea regarding the cause of the patency and management of the condition.

As this study is done in rural setup patients are not always affordable for diagnostic laparoscopic chromopertubation, so the first line of management remains to be Hysterosalphingography and as it's a non invasive and low cost which should be followed by Diagnostic laparoscopic chromopertubation.

\section{CONCLUSION}

The results suggest that hysterosalpingography is useful as a primary screening procedure, but laparoscopy provides a more accurate assessment of tubal patency in the investigation of infertility. In planning of tubal microsurgeries both will be complementary to each other.

\section{Funding: No funding sources \\ Conflict of interest: None declared \\ Ethical approval: The study was approved by the Institutional Ethics Committee}

\section{REFERENCES}

1. Cui W. Mother or nothing: the agony of infertility. Bull World Health Organ. 2010;88:881-2.

2. Chachamovich JR, Chachamovich E, Ezer H, Fleck MP, Knauth D et al. Investigating quality of life and health-related quality of life in infertility: a systematic review. J Psychosom Obstet Gynaecol. 2010;31:101-110.

3. Foroozanfard F, Sadat Z. diagnostic value of hysteroslpingography and laparoscopy for tubal patency in infertile women. Nurs midwifery stud. 2013;2(2):188-92

4. Lim CP, Hasafa Z, Bhattacharya S, Maheshwari A. Should a Hysterosalpingogram Be a First-Line Investigation to Diagnose Female Tubal Sub fertility in the Modern Sub fertility Workup? Hum Reprod. 2011;26(5):967-71.

5. Santhalia PK, Gupta MK, Uprety D, Ahmad K, Ansari S, Agrawal $\mathrm{N}$ et al. Role of radiographic 
Hysterosalpingography in Infertility in Eastern Nepal. NJR. 2013;13(1):59-66.

6. World Health Organization. Infections, pregnancies and infertility: perspectives on prevention. Fertil Steril.1987;47(6):964-8.

7. Nachtigall RD. International disparities in access to infertility services. Fertil Steril. 2006;85(4):871-5.

8. Otolorin EO, Ojengbede O, Falase AO. Laparoscopic evaluation of the tuboperitoneal factor in infertile Nigerian women. Int $\mathbf{J}$ Gynecol Obstet. 1987;25(1):47-52.

9. Balasch J. Investigation of the infertile couple in the era of assisted reproductive technology: a time for reappraisal. Hum Reprod. 2000;15(11):2251-7.

10. Swart P, Mol BW, Van der Veen F, Van Beurden M, Redekop WK, Bossuyt PM. The accuracy of hysterosalpingography in the diagnosis of tubal pathology: a meta-analysis. Fertil Steril. 1995;64(3):486-91.

11. Swart P, Mol BW, van der Veen F, van Beurden M, Redekop WK, Bossuyt PM. The accuracy of hysterosalpingography in the diagnosis of tubal pathology: a meta-analysis. Fertil Steril. 1995;64:486.

12. Cook ID. Infertility. In: Edmonds DK, Dewhurst J, editors. Dewhurst's Textbook of Obstetrics and Gynaecology for Postgraduates. Oxford; Malden, MA: Blackwell Science; 1999:433.
13. Park JJ, Kang M, Shin S, Choi E, Kwon S, Wee H, Nam B, Kaptchuk TJ. Unexplained infertility treated with acupuncture and herbal medicine in Korea. J. Kaptchuk J Altern Complement Med. 2010 Feb; 16(2):193-8.

14. Chakraborti DK, Kole SK. Diagnostic laparoscopy in gynaecological disorder. J Obstet Gynecol. 1990;40:262-5.

15. Goynumer G, Yetim G, Gokcen O, Karaaslan I, Wetherilt L. Hysterosalpingography, Laparoscopy, the diagnosis of tubal disease In infertility. World J Laparoscopic Surg. 2008;1(2):23-26.

16. Sharma R, Sharma V. The infertile woman: a study of 120 cases. J Indian Med Assoc. 1991;89(2):31-2.

17. Swart P, Mol BW, van der Veen F, van Beurden, Redekop WK, Bossuyt PM. The accuracy of hysterosalpingography in diagnosis of tubal pathology: a metaanalysis. Fertil Steril. 1995;64:48691.

Cite this article as: Choudhary A, Tiwari S. Comparison between hysterosalpingography and laparoscopic chromopertubation for the assessment of tubal patency in infertile women. Int J Reprod Contracept Obstet Gynecol 2017;6:4825-9. 